\title{
A Capacitance Estimation of Film Capacitors in an LCL-Filter of Grid-Connected PWM Converters
}

\author{
Hong-Jun Heo*, Won-Sang Im$^{*}$, Jang-Sik Kim ${ }^{* *}$, and Jang-Mok Kim ${ }^{\dagger}$ \\ ${ }^{\dagger *}$ School of Electrical Engineering, Pusan National University, Busan, Korea \\ ${ }^{* *}$ Control Team, Motor BU Division, LG Electronics, Changwon, Korea
}

\begin{abstract}
A capacitor deterioration of LCL-filter grid-connected PWM converters is progressed by the self-healing mechanism. It leads to the degradation of the filter performance and drop of power factor. Thus, it is required to diagnose fault-point of capacitors and determine the replacement time. Typically, the fault of capacitors is determined when the capacitance is reduced up to $80 \%$ from initial value. This paper proposes algorithm to the determine capacitor replacement time of an LCL filter. The algorithm takes the advantage of change of the response on the injected resonant frequency corresponding to $80 \%$ value from the initial capacitance. The results of the algorithm are demonstrated through simulations and experiments.
\end{abstract}

Key words: Deterioration of film capacitor, Grid connected PWM converter, Injection of resonant frequency, LCL filter

\section{INTRODUCTION}

In recent years, grid-connected ac/dc PWM converters have become the standard in industrial applications owing to their advanced features including sinusoidal input currents with unity power factor and high-quality dc output voltages, and the ability to work in rectifying and regenerating mode such as wind power and solar power [1], [2]. In the operation of grid-connected PWM converters, fulfillment for current harmonic restrictions is one of the critical issues. The use of pulse width modulation (PWM) in conjunction with closed-loop current control allows a sinusoidal input current to be achieved with a total harmonic distortion (THD) below $5 \%$ [3]-[7].

Typical power device switching frequencies of between $2 \sim 15 \mathrm{kHz}$ can cause high-order harmonics that can disturb other sensitive loads and equipments on the grid [8]. Accordingly, L filters or LCL filters are mainly inserted between the grid and converter to reduce harmonic components from PWM switching. Determination of the filter parameters is a crucial design factor to enhance cost-effectiveness of the

Manuscript received Oct. 7, 2011; revised Sep. 22, 2012

Recommended for publication by Associate Editor Han-Ju Cha.

${ }^{\dagger}$ Corresponding Author : jmok@pusan.ac.kr

Tel: +82-51-510-2366, Fax: +82-51-513-0212, Pusan Nat'l University

${ }^{*}$ School of Electrical Eng., Pusan National University, Korea

${ }^{* *}$ Control team, Motor BU Division, LG Electronics, Korea system. In the case of L filters, a high input inductance should be used to reduce the current harmonics around the switching frequency. However, for applications above several kilowatts, it becomes quite expensive to realize higher value filter reactors. Moreover, the system dynamic response may become poor.

An alternative and attractive solution to this problem is to use an LCL filter as shown in Fig. 1. With this solution, optimum results can be obtained in the range of power levels up to hundreds of kilovolt-amperes, still using quite small values of inductors and capacitors [9]. From an economical point of view, LCL filters are more attractive because stronger harmonics attenuation is relatively achievable compared to the same size L filters and, consequently, lower switching frequency is allowable in the case of the same harmonic current limitation. For this reason, LCL filters are more significant and increasingly used [10]-[12].

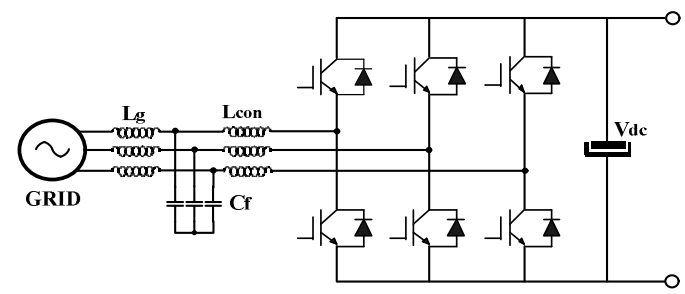

Fig. 1. Grid-connected three-phase PWM converter. 


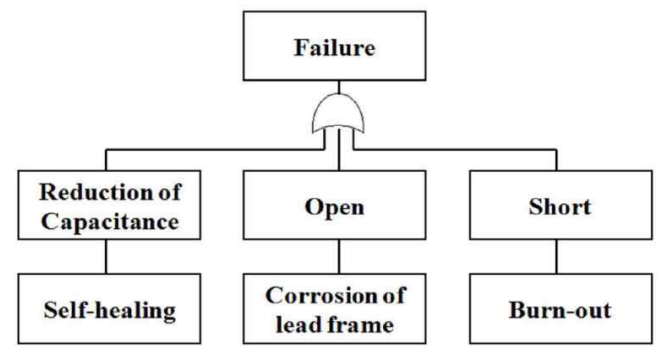

Fig. 2. FTA(Fault Tree Analysis) of MPPF Capacitor.

As a third-order system, the LCL-filter tends to resonate at the resonance frequency, which endangers system stability. The resonance issue can be solved by active damping [13][14] or passive damping [15].

Another issue of LCL filters is deterioration of metalized polypropylene film (MPPF) capacitors. The MPPF capacitors are used in the LCL filter of the grid-connected PWM converter due to their good reliability and good frequency characteristics.

The MPPF capacitors at max rated conditions typically have service life ratings in the range from 60,000 hours to 150,000 hours. It is not practical to do life testing on AC polymeric film capacitors using max rated conditions since the test would last for many years [16].

However, the MPPF capacitors lifetime can be significantly reduced by use for a long time with a large harmonic current, ripple voltage, hot spot temperature and harsh environments. Typically, the failure of a capacitor is determined when the capacitance is reduced up to $80 \%$ from the initial value. The reasons of failures are the self-healing mechanism, corrosion of lead frame or burn-out as shown in Fig. 2 [17].

Especially, the self-healing mechanism of MPPF capacitors is the main cause of reduction in capacitance and increase in the equivalent series resistance (ESR) with aging as shown in Fig. 3. When a foil capacitor suffers dielectric breakdown, the electrodes become connected through a low impedance connection at the point where the fault occurred. At this point, the part of the capacitor where the fault occurred is normally a short circuit and unable to accept a charge. This problem does not exist for the self-healing metalized electrode capacitors. With a self-clearing electrode, the fault in the dielectric will result in the thin metalized electrode in the immediate area of the fault being vaporized or turned from a metal conductor into a metal oxide insulator. If the fault should occur in the dielectric as shown in Fig. 3, the current will flow from one end sprayed connection, through one electrode, through the fault, to the opposite electrode and to the opposite end sprayed termination. The current in the area of the fault will be trying to go through the metal conductor that is so thin that it is optically translucent. The amount of a current that can go through this thin electrode is very limited. The electrode in the immediate distance of the fault will be blown away; the current will be safely interrupted because this process and a fuse operation are similar. Once the fault has been cleared, as shown in Fig.4, the

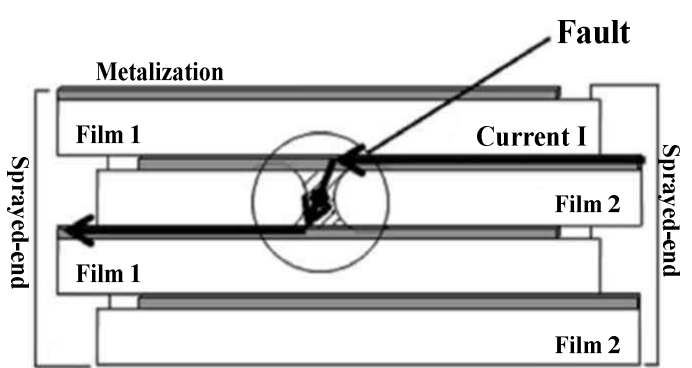

Fig. 3. Mechanism of clearing in a MPPF capacitors: presence of a fault in the dielectric film.

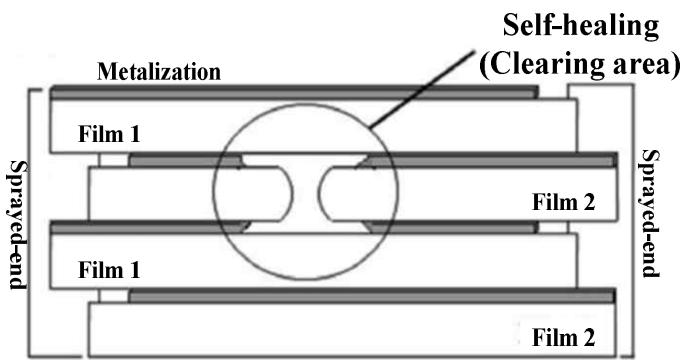

Fig. 4. Evaporation of the metal with the only measurable damage being a small loss of capacitance.

capacitor will continue to function with the only measurable damage being a small loss of capacitance [18], [19].

The capacitor deterioration from the self-healing mechanism leads to degradation of a filter with increase in THD of the grid. In addition, it causes drop of power factor in grid-connected PWM converter systems.

This paper proposes an algorithm in order to determine the capacitor replacement time of the LCL filter when the capacitance is reduced up to $80 \%$ from the initial value. The algorithm takes the advantage of change of the response on the injected resonant frequency corresponding $80 \%$ from the initial capacitance.

\section{EFFECTS ON GRID-CONNECTED CONVERTER BY CAPACITOR DETERIORATION OF LCL FILTER}

In grid-connected PWM converters, the capacitor deterioration of the LCL filter causes the decrease of its capacitance. Then, the resonant frequency of the filter moves toward switching frequency of the system as shown in Fig. 5. As a result, it involves adverse effects on the system.

First of all, one of adverse effects is performance degradation of the LCL filter. THD of grid-side increases depending on the decrease of capacitance. The resonant frequency of initial capacitance is shown as in (1). When the capacitance is reached in diminished point up to $80 \%$ of initial capacitance, the fault of capacitor is determined; the resonant frequency of fault point can be gained as in (2). At a fault point of a capacitor, the resonant frequency increase 1.118 times when compared to the initial value as in (3). 


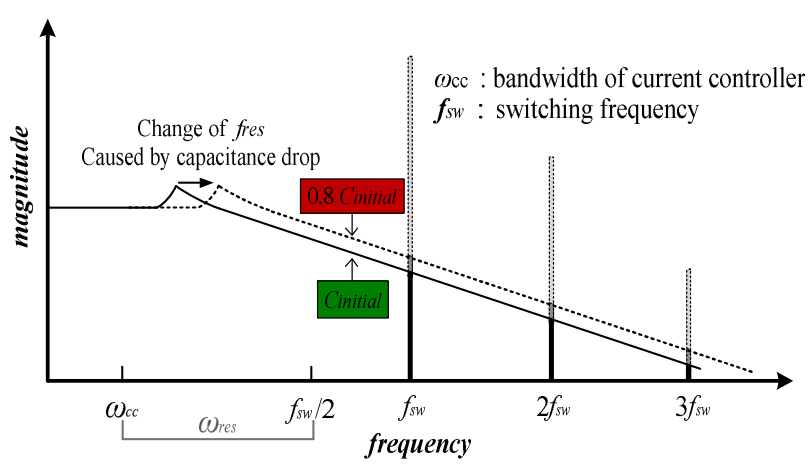

Fig. 5. Degradation of filter caused by capacitor deterioration.

$$
\begin{gathered}
f_{\text {res_initial }}=\frac{1}{2 \pi} \sqrt{\frac{L_{\text {con }}+L_{g}}{L_{c o n} \times L_{g} \times C_{\text {intial }}}} \\
f_{\text {res_fault }}=\frac{1}{2 \pi} \sqrt{\frac{L_{\text {con }}+L_{g}}{L_{\text {con }} \times L_{g} \times 0.8 C_{\text {intial }}}} \\
f_{\text {res_fault }}=1.118 \times f_{\text {res_initial }}
\end{gathered}
$$

Also, the capacitance reduction causes drop of power factor. In an LCL-filter based three-phase PWM converter, current sensors are located in a reactor of the converter-side as shown in Fig. 6. Therefore, three-phase current of the converter-side makes it possible to have a unity power factor control with three-phase voltage of the grid. However, in the initial design of the LCL filter, filter-side capacitors and grid-side reactors have to be designed to be more than $95 \%$ of unity power factor because the phase current of the grid-side are outside the control domain of the converter system.

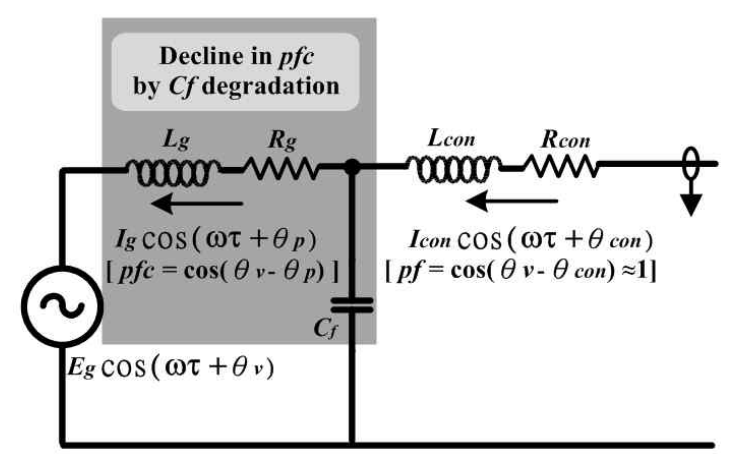

Fig. 6. Drop of power factor caused by capacitor deterioration.

According to (4), (5) and (6), if initial capacitance decreases up to $80 \%$, the power factor correction $(p f c)$ in a fault condition is to be 0.931 times as compared with the initially designed $p f_{c}$ as in (7).

$$
\begin{gathered}
Z_{g}=R_{g}+j X_{g} \quad Z_{c}=j X_{c} \\
Z_{p}=\frac{Z_{g} \cdot Z_{c}}{Z_{g}+Z_{c}}=R_{P}+j X_{P} \\
=\frac{R_{g} X_{c}^{2}}{R_{g}^{2}+\left(X_{g}+X_{c}\right)^{2}}+j \frac{R_{g}^{2} X_{c}+\left(X_{c}+X_{g}\right) X_{g} X_{c}}{R^{2}+\left(X_{g}+X_{c}\right)^{2}} \\
p f_{c_{\text {initial }}}=\cos \left(\theta_{v}-\theta_{p}\right)=\cos \left(\tan ^{-1} \frac{X_{p}}{R_{p}}\right) \\
=\cos \left(\tan ^{-1} \frac{R^{2}+\left(X_{c}+X_{g}\right) X_{g}}{R X_{c}}\right) \\
p f c_{\text {fault }}=\cos \left(\theta_{v}-\theta_{p}\right)=\cos \left(\tan ^{-1} \frac{X_{p}}{R_{p}}\right) \\
=\cos \left(\tan ^{-1} \frac{R^{2}+\left(0.8 X_{c}+X_{g}\right) X_{g}}{0.8 X_{c} R}\right)
\end{gathered}
$$

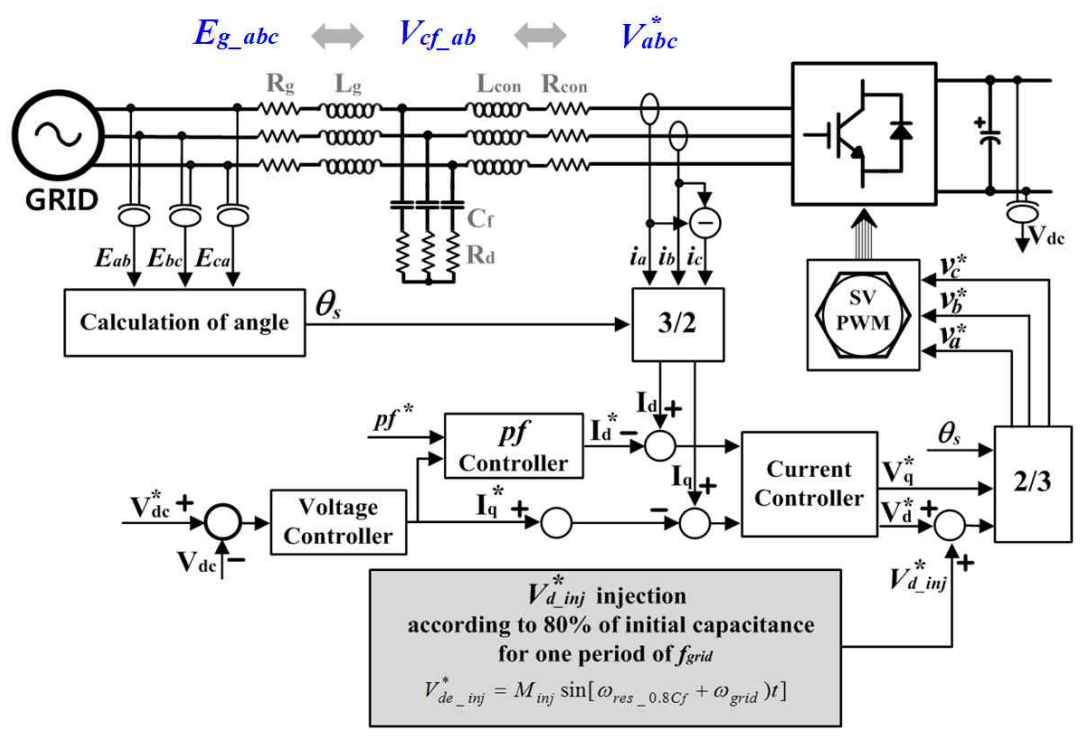

Fig. 7. The control block of grid-connected PWM converter for proposed diagnosis. 


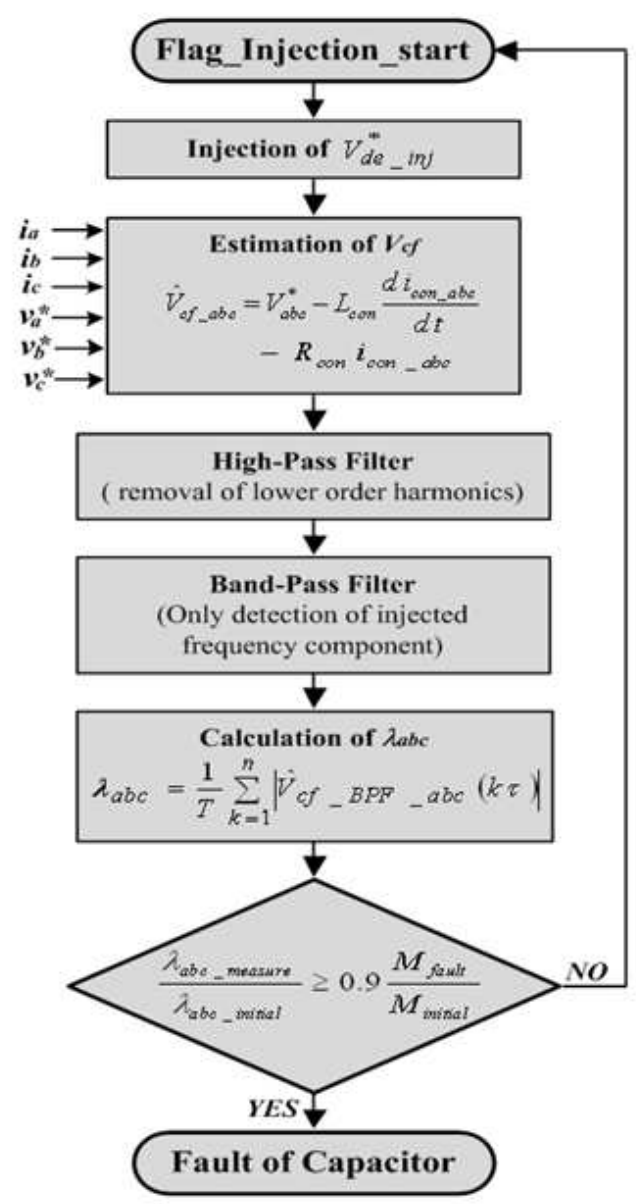

Fig. 8. The flowchart for proposed diagnosis.

$$
p f c_{\text {fault }}=0.931 \times p f c_{\text {initial }}
$$

\section{AlgORIthMS FOR RePlacement TIME AND DETERIORATION DIAGNOSIS OF CAPACITOR IN LCL FILTER}

The block diagram of a three-phase grid-connected PWM converter system for the diagnosis is shown in Fig.7; Fig.8 shows the flowchart for the proposed diagnosis and replacement time of the filter-side capacitor.

\section{A. Injection of resonant frequency component} corresponding to fault capacitance value

In the proposed algorithms, the resonant frequency of the capacitor fault point is used to detect the capacitor replacement time as shown in Fig.9. When the resonant frequency is moved by the decrease in capacitance, the response gain to the injection component is increased from A-point to B-point due to the changed transfer function of the LCL filter.

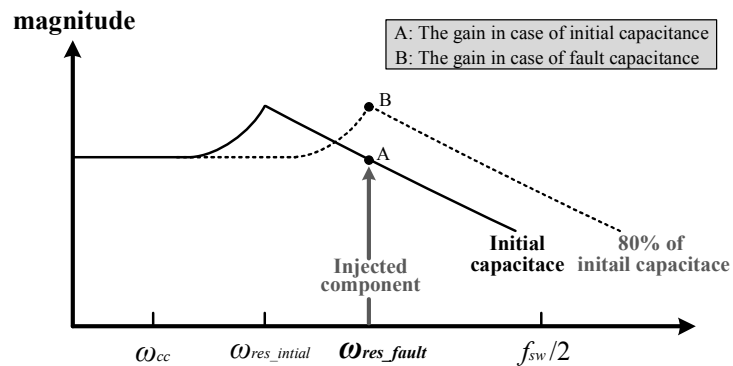

Fig. 9. Change of Bode-plot by capacitor deterioration of LCL

The injection of the resonant frequency component is performed in the $d$-axis reference voltage during one period of the grid fundamental frequency as shown in Fig.7. It is because the active power (q-axis component) is almost unaffected and the diagnosis of capacitor deterioration is possible to be independent of the load.

As shown in (8), the component that adds the resonant frequency of the capacitor fault-point and the fundamental frequency of the grid is injected into the $d$-axis reference voltage. Next, using the $d q$ inverse transform, the injected component in $d$-axis voltage reference is transformed into the reference phase voltage (10) through (9). The injected resonant component of the reference phase voltage affects the capacitor voltage of the LCL-filter according to the gain of the LCL transfer function.

$$
\begin{aligned}
& V_{d e_{-} i n j}^{*}=M_{i n j} \sin \left[\left(\omega_{\text {res_fault }}+\omega_{\text {grid }}\right) t\right] \\
& V_{d s_{-} i n j}^{*}=\frac{M_{i n j}}{2} \sin \left(\omega_{\text {res_fault }} t\right)-\frac{M_{i n j}}{2} \sin \left[\left(\omega_{\text {res_fault }}+2 \omega_{\text {grid }}\right) t\right] \\
& V_{q s_{-} i n j}^{*}=\frac{M_{i n j}}{2} \cos \left(\omega_{\text {res_fault }} t\right)-\frac{M_{i n j}}{2} \cos \left[\left(\omega_{r_{\text {re__fault }}}+2 \omega_{\text {grid }}\right) t\right] \\
& V_{a_{-} i n j}^{*}=\frac{M_{i n j}}{2} \sin \left(\omega_{\text {res_fault }} t\right)-\frac{M_{i n j}}{2} \sin \left[\left(\omega_{\text {res_fault }}+2 \omega_{\text {grid }}\right) t\right] \\
& V_{b_{-} i n j}^{*}=\frac{M_{i n j}}{2} \sin \left(\omega_{\text {res_fault }} t-\frac{2}{3} \pi\right)-\frac{M_{i n j}}{2} \sin \left[\left(\omega_{\text {res_fault }}+2 \omega_{\text {grid }}-\frac{2}{3}\right.\right. \text {. } \\
& V_{c_{-} i n j}^{*}=\frac{M_{i n j}}{2} \sin \left(\omega_{\text {res_f fault }} t+\frac{2}{3} \pi\right)-\frac{M_{i n j}}{2} \sin \left[\left(\omega_{\text {res_fault }}+2 \omega_{\text {grid }}+\frac{2}{3} \pi\right) t\right]
\end{aligned}
$$

\section{B. Voltage estimation of capacitor in LCL filter}

The capacitor-side voltages of Fig. 10 can be estimated by (11) due to sensing of the converter-side current and parameters of the LCL-filter.

$$
\hat{v}_{c f_{-} a b c}=v_{a b c}^{*}-L_{c o n} \frac{d i_{c o n \_a b c}}{d t}-R_{c o n} i_{c o n \_a b c}
$$

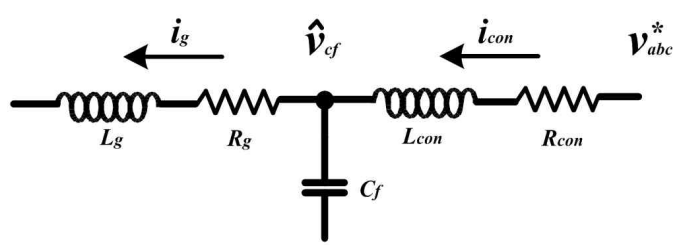

Fig. 10. Single-phase equivalent circuit for voltage estimation of film capacitor side. 


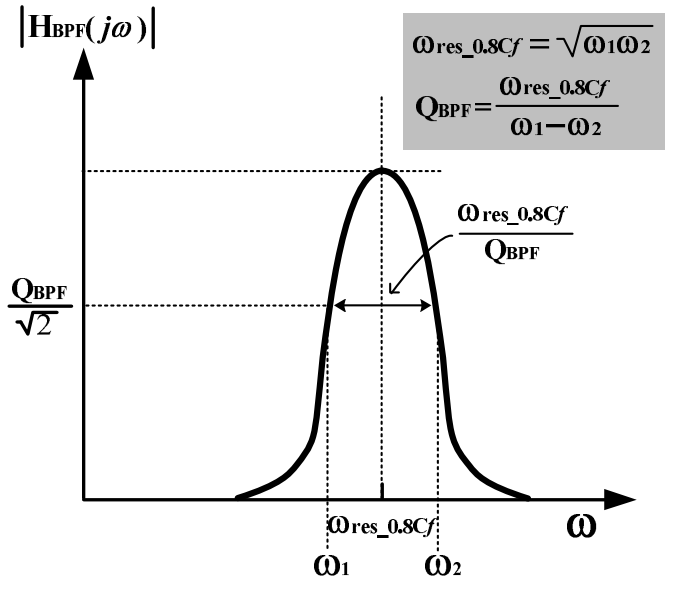

Fig. 11. Quality factor and Gain curve of Band Pass Filter.

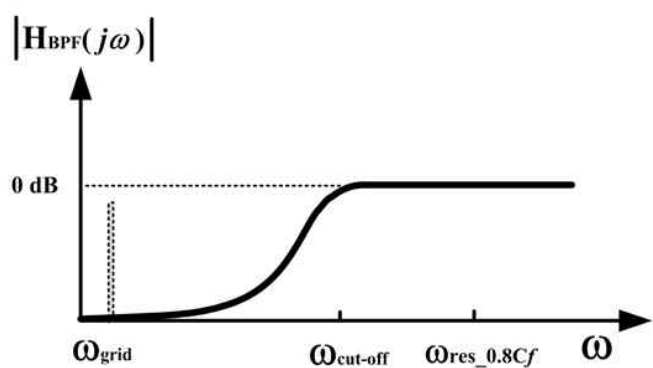

Fig. 12. Gain curve of High Pass Filter.

C. Detection of Only Response on the Injection Component in Estimated Capacitor Voltage

The second-order band pass filter (BPF) is used to detect of response on the injected resonant frequency component in the estimated capacitor-side voltage. The transfer function of the BPF is shown in (12). Quality factor, band-width and gain curve of BPF can be confirmed in Fig.11. Also, high pass filter (HPF) needs to remove the unnecessary low-order harmonic components as in (13) and Fig. 12. Also, with regard to grid frequency harmonics, the cut-off frequency of the HPF has to be selected [20].

$$
\begin{gathered}
\hat{V}_{c f_{-} B P F_{-} a b c(s)}=\frac{K_{B P F}\left(\omega_{\text {res_ } 0.8 C f} / Q_{B P F}\right) s}{s^{2}+\left(\omega_{\text {res_ } 0.8 C f} / Q_{B P F}\right) s+\omega_{\text {res_- }_{-} 0.8 C f}^{2}} \hat{V}_{c f_{-} a} . \\
\hat{V}_{c f_{-} H P F_{-} a b c(s)}=\frac{s}{s+\omega_{c u t_{-} o f f}} \hat{V}_{c f_{-} B P F_{-} a b c(s)}
\end{gathered}
$$

\section{Detection for Replacement Time of Capacitor}

The estimated capacitor voltage through the BPF and HPF is averaged by (14). Average capacitor voltage ( $\left.V_{\text {cf_ave_abc_initial }}\right)$ in initial capacitance must remember because it is used as standard value for diagnosis. Since then, periodically measured average capacitor voltage ( $\left.\hat{V}_{\text {cf_ave_abc_measured }}\right)$ is compared with $V_{c f \_a v e \_a b c \_i n i t i a l}$ as in (15). According to the progress of the capacitor deterioration, the proportion value $\gamma_{a b c}$ by experiment continues to increase until the capacitance-decrease reaches $80 \%$ point of the initial capacitance.

$$
\begin{gathered}
\hat{V}_{c f_{\_} a v e \_a b c}=\frac{1}{T} \sum_{k=1}^{n}\left|\hat{V}_{c f_{-} B P F_{-} a b c}(k \tau)\right| \\
\gamma_{a b c}=\frac{\hat{V}_{c f \_a v e \_a b c \_m e a s u r e d}}{\hat{V}_{c f \_a v e \_a b c \_i n i t i a l}}
\end{gathered}
$$

In addition, through the transfer function (16) of the LCL-filter, the magnitude gain according to each frequency can be calculated exactly. Consequently, the magnitude gain of response on the injected frequency component $\omega_{i n j}$ can be obtained by using (16) and (17).

$$
\begin{gathered}
s M(s)=\frac{\frac{R_{d}}{L_{c o n} L_{g}} s+\frac{1}{C L_{c o n} L_{g}}}{s^{2}+\left(\frac{R_{d}}{L_{c o n}}+\frac{R_{d}}{L_{g}}\right) s+\left(\frac{L_{c o n}+L_{g}}{C L_{c o n} L_{g}}\right)} \\
k_{1}=\frac{R_{d}}{L_{c o n} L_{g}} \quad k_{2}=\frac{1}{L_{c o n} L_{g}}, \omega_{r e s}=\sqrt{\frac{L_{c o n}+L_{g}}{C L_{c o n} L_{g}}}, \quad \zeta=\frac{1}{2 \omega_{r e s}}\left(\frac{R_{d}}{L_{c o n}}+\frac{R_{d}}{L_{g}}\right)
\end{gathered}
$$

Before the deterioration of a capacitor, when the capacitance of the filter-side capacitor keeps the initial value, the magnitude gain is expressed as in (18). However, if the capacitance decreases up to the fault-point, the magnitude gain is calculated as in (19) because the injected frequency is equal to the resonant frequency of the LCL-filter. The proportion value $\rho$ of (20) and (21) by calculation of the transfer function is shown in (20).

$$
\begin{gathered}
\omega_{i n j} M_{\text {intial }}=\frac{k_{1} \omega_{i n j}+k_{2} / C_{f_{-} \text {initial }}}{\sqrt{\left(\omega_{\text {res_initial }}^{2}-\omega_{i n j}^{2}\right)^{2}+\left(2 \zeta \omega_{\text {res_initial }} \omega_{\text {inj }}\right)^{2}}} \\
\omega_{\text {inj }} M_{\text {fault }}=\left.\frac{k_{1} \omega_{i n j}+k_{2} / C_{f_{-} \text {fault }}}{2 \zeta \omega_{\text {inj }}}\right|_{\omega_{\text {res }}=\omega_{i n j}} \\
\rho=\frac{\omega_{\text {inj }} M_{\text {fault }}}{\omega_{i n j} M_{\text {initial }}}
\end{gathered}
$$

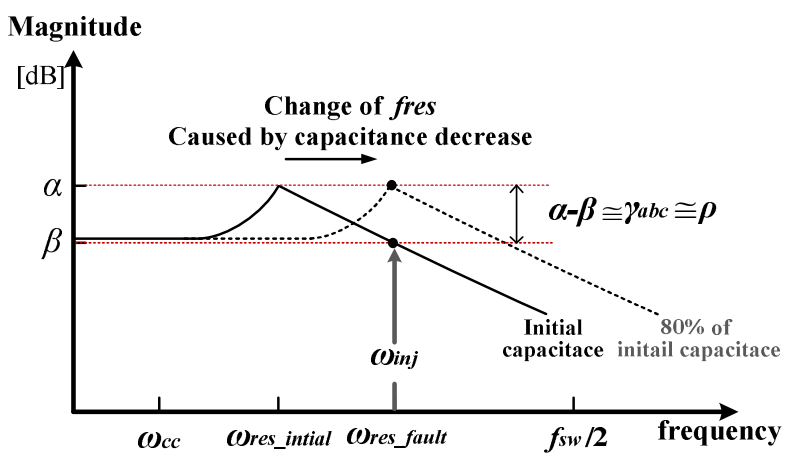

Fig. 13. Difference of $\mathrm{dB}$ gain between initial capacitance and faulty capacitance. 


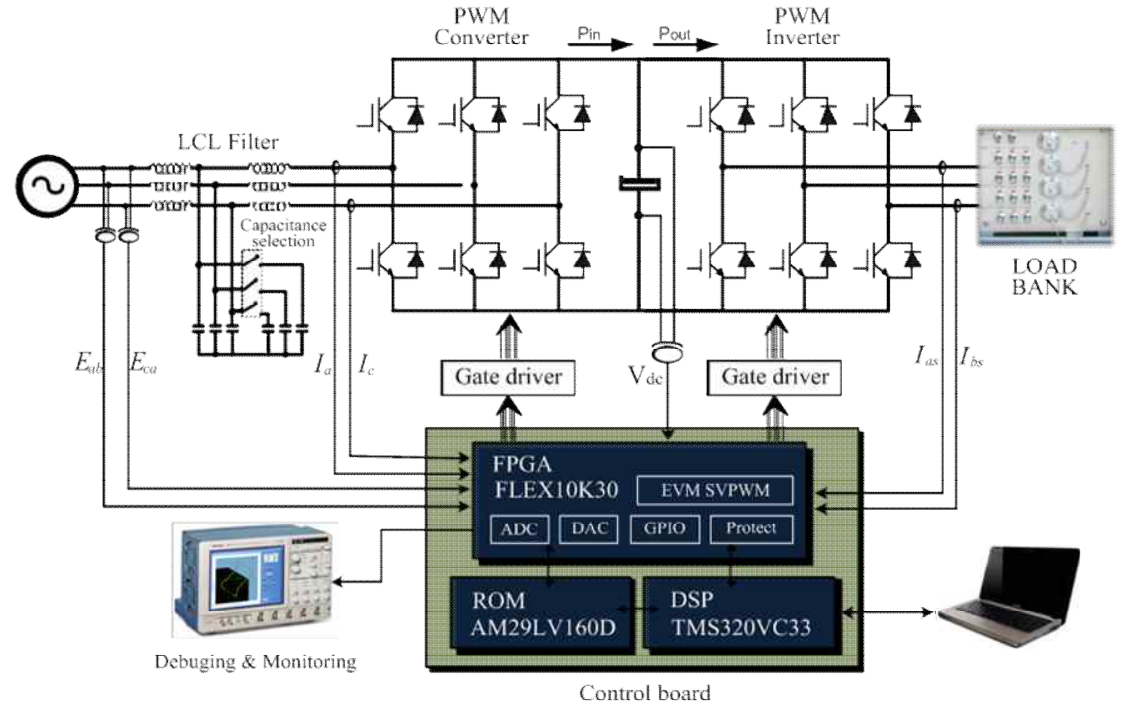

Fig. 14. Configuration of experimental system.

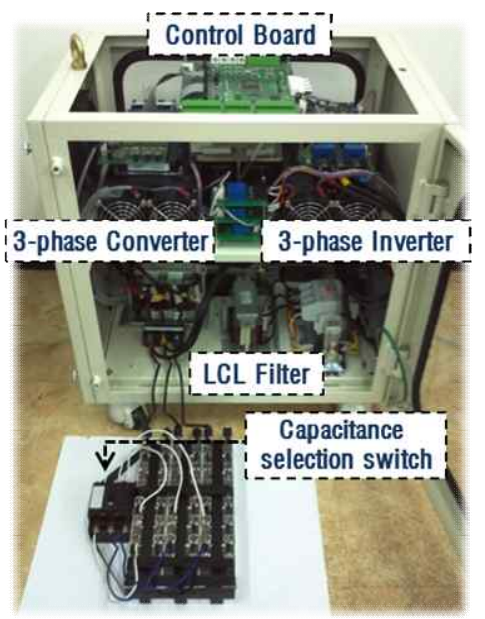

Fig. 15. Experimental setup.

TABLE I

SIMULATION AND EXPERIMENT CONDITIONS

\begin{tabular}{|c|c|c|c|c|c|}
\hline \multicolumn{2}{|c|}{ Simulation \& Experiment conditions } & \multicolumn{2}{|c|}{ Design of LCL filter } & \multicolumn{2}{|c|}{ Capacitance selection } \\
\hline Grid voltage & $3 \mathrm{P} 220 \mathrm{~V} r m s 60 \mathrm{~Hz}$ & Grid-side $L g$ & $0.15 \mathrm{mH}$ & \multirow{2}{*}{ Switch ON } & \multirow{2}{*}{$\begin{array}{r}f r e s=2185 \mathrm{~Hz} \\
{[38 \mathrm{uF}(100 \%)]}\end{array}$} \\
\hline Controlled Vdc & $500 \mathrm{~V}$ & Converter-side Lcon & $2 \mathrm{mH}$ & & \\
\hline Switching frequency & $10 \mathrm{kHz}$ & $C_{f_{-} \text {initial }}$ & 38 uF $(100 \%)$ & \multirow{2}{*}{ Switch OFF } & \multirow{2}{*}{$\begin{array}{c}\text { fres }=2440 \mathrm{~Hz} \\
{[30 \mathrm{uF}(80 \%)]}\end{array}$} \\
\hline Pout & $3 \mathrm{~kW}$ & Cf fault & $30 \mathrm{uF}(80 \%)$ & & \\
\hline
\end{tabular}

As a result, the deterioration fault of the filter-side capacitor is determined through comparison between experimental $\gamma_{a b c}$ and calculated $\rho$ as shown in (21). By multiplying the gain of 0.9 , the fault flag of the capacitor occurs when the capacitance decreases up to $82 \%$. The difference in $\mathrm{dB}$ is almost equal to the experimental value and calculated value as shown in Fig. 13. However, the value 0.9 needs to be multiplied in order to improve the reliability of the diagnosis because there could be a slight error.

$$
\gamma_{a b c} \geq 0.9 \rho
$$

The configurations of the experimental system and experimental setup are shown in Fig. 14 and Fig. 15, respectively. A high-performance DSP chip (TMS 320VC33) was used as a main controller, which operates at a $33.3-\mathrm{MHz}$ clock frequency and is capable of 32-bit floating-point operation. The sampling period is 50us. The $22 \mathrm{kWatt}$ three-phase back-to-back converter with the LCL-filter and the 3 kWatt load bank are used as shown in Fig. 14. The simulation and experimental conditions are listed in Table I. The switching frequency is $10 \mathrm{kHz}$, and the resonance of the LCL-filter is designed as $2185 \mathrm{~Hz}$. As a matter of fact, in order to prove the algorithm, the capacitor of LCL-filter is designed to be able to select between the initial value $38 \mathrm{uF}$ and the fault value $30 \mathrm{uF}$.

Fig. 16 shows the movement of the bode plot according to the increase of the resonant frequency caused by the capacitor deterioration. Because the fault of the capacitor is determined when the capacitance is reduced up to $80 \%$ from the initial value, the $2,440 \mathrm{~Hz}$ component is injected to determine the replacement time of filter-side capacitors.

In this paper, only a-phase is used for the proof of the algorithm in order to avoid redundancy.

The component (22) that adds $2,440 \mathrm{~Hz}$ for the diagnosis and the fundamental frequency $60 \mathrm{~Hz}$ of the grid is injected into $d$-axis voltage reference voltage during one period of the grid frequency as shown in Fig. 17. It is possible to confirm that $q$-axis reference voltage to active power component is almost unaffected. Then, by using the $d q$ inverse transform, (22) is transformed into a-phase reference voltage (23) as shown in Fig. 18.

$$
V_{d e_{-} i n j}^{*}=20 \sin [(2 \pi \cdot 2500) t]
$$

$$
V_{a}^{*}=10 \sin (2 \pi \cdot 2440 t)-10 \sin (2 \pi \cdot 2560 t)
$$




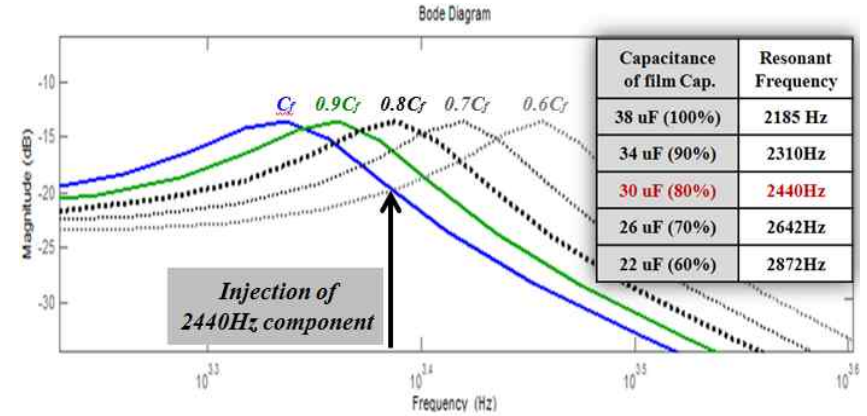

Fig. 16. Movement of resonant frequency caused by capacitor deterioration.

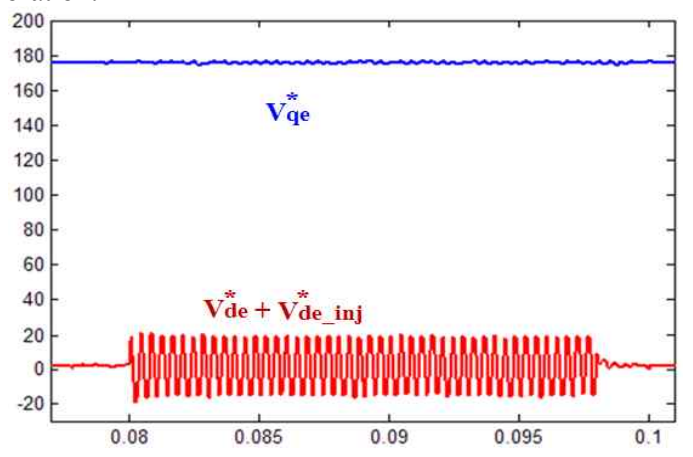

(a) Simulation.

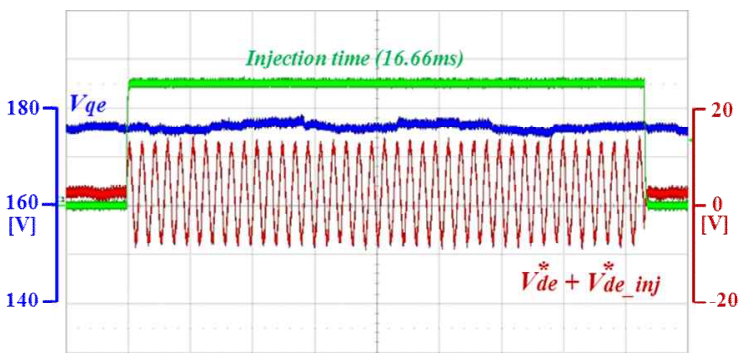

(b) Experiment.

Fig.17. Injection of $2500 \mathrm{~Hz}$ element to $d$-axis voltage reference.

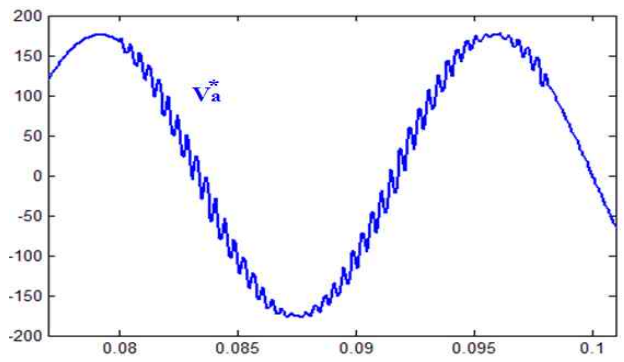

(a) Simulation.

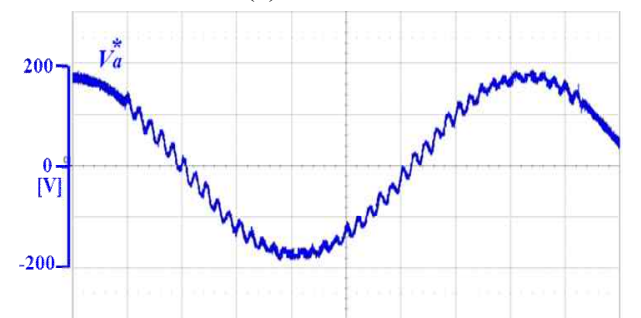

(b) Experiment.

Fig. 18. $V_{a}^{*}$ by dq inverse transformation of $V_{d e}^{*}$
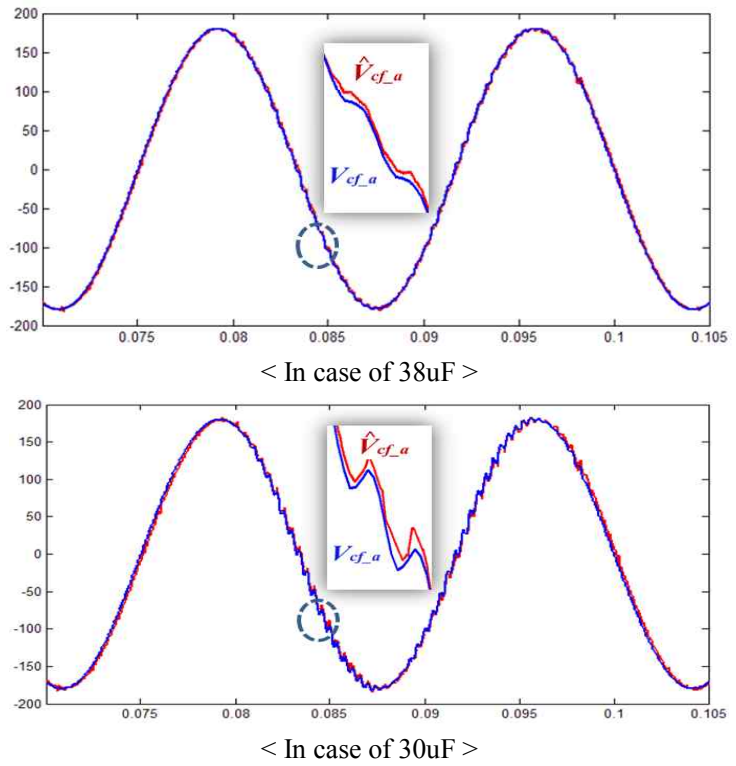

(a) Simulation.

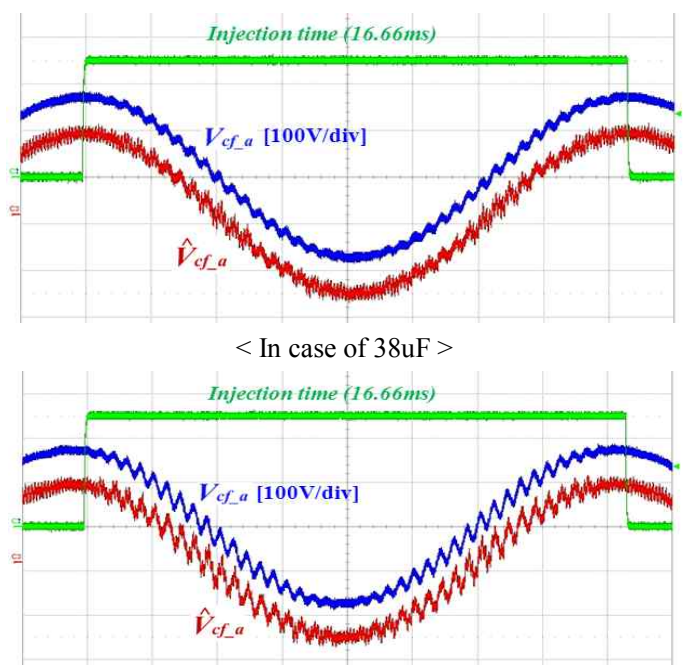

$<$ In case of $30 \mathrm{uF}>$

(b) Experiment.

Fig. 19. Voltage tracking of film capacitor side.

The filter-side capacitor voltage can be estimated by (10) like results of Fig. 19. It can also find the estimated voltage. Allowing the deterioration of the capacitor from $38 \mathrm{uF}$ to $30 \mathrm{uF}$, ripples of the capacitor-side voltage is increased by the injected resonant frequency component. It is because the magnitude gain of the injected component has the largest gain at $30 \mathrm{uF}$.

The second-order BPF is used to detection of the ripple component $(2,440 \mathrm{~Hz})$ in the estimated voltage as shown in Fig. 20. The digital filter of the second-order BPF is designed to have the 50 us sampling time, the bandwidth of 20 as in (24). Averaged $V_{\text {cfave } a} a$ in the case of $38 \mathrm{uF}$ has to be set as the standard value for the diagnosis. When the capacitance of $38 \mathrm{uF}$ is decreased down to $30 \mathrm{uF}, \hat{V}_{\text {cf_ave_a }}$ represents the largest value because of the largest magnitude gain as shown in Fig.16. 

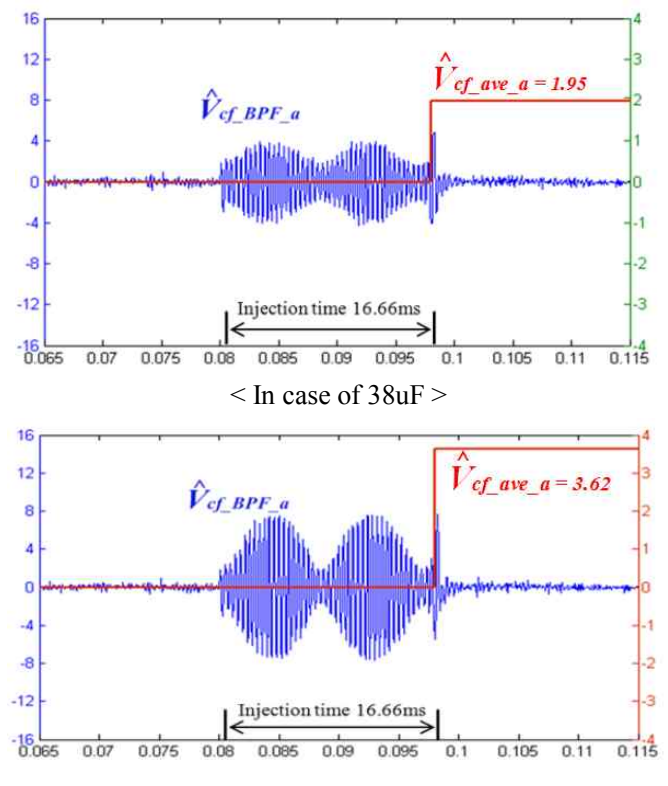

$<$ In case of $30 \mathrm{uF}>$

(a) Simulation.

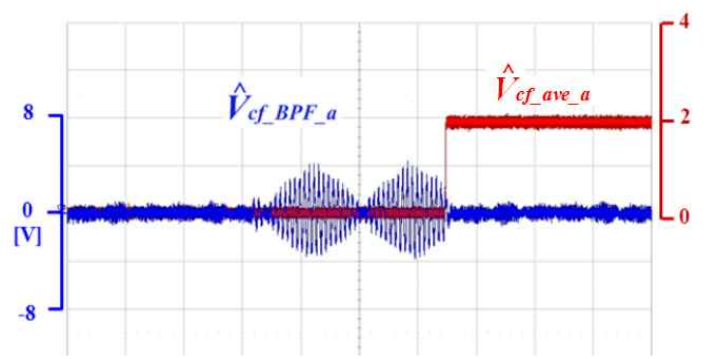

$<$ In case of $38 \mathrm{uF}>$

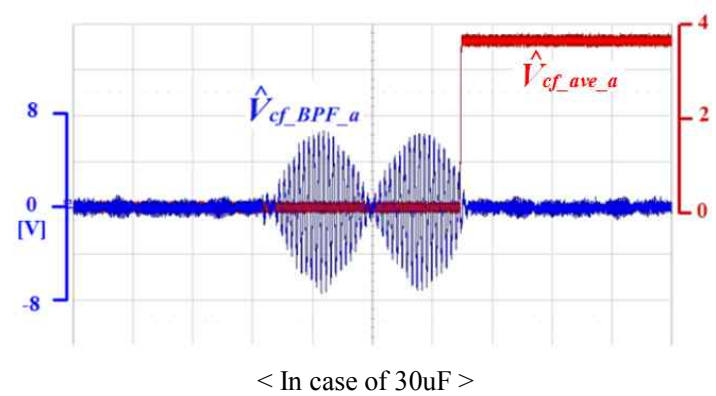

(b) Experiment.

Fig. 20. Detection of $2440 \mathrm{~Hz}$ component using BPF.

$$
\begin{aligned}
& \hat{V}_{c f_{-} B P F_{-} a}(n)=\frac{20 T_{\text {samp }}\left(\hat{V}_{c f_{-} H P F_{-} a}(n)-\hat{V}_{c f_{-H P F_{-} a}}(n-1)\right)}{1+20 T_{\text {samp }} \omega_{B P F^{2}}^{2} T_{\text {samp }}^{2}}
\end{aligned}
$$

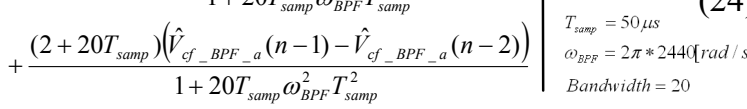

In Fig. 21, the HPF is used to remove unnecessary component because the estimated capacitor voltage is dominated by $60 \mathrm{~Hz}$ and low-order harmonic. If the HPF is not used to diagnosis, the error rate of the diagnosis can go up. The digital HPF as shown in (25) is designed to remove up to $13^{\text {th }}$ harmonic.
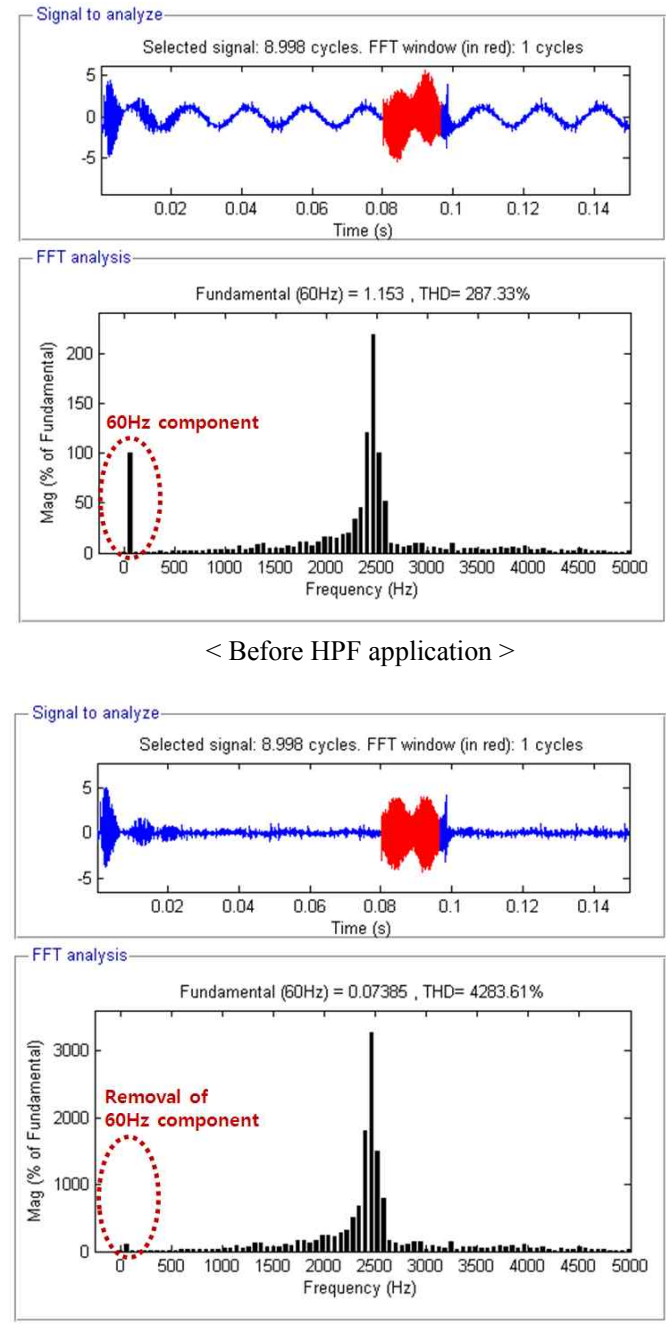

$<$ After HPF application >

(a) Simulation.

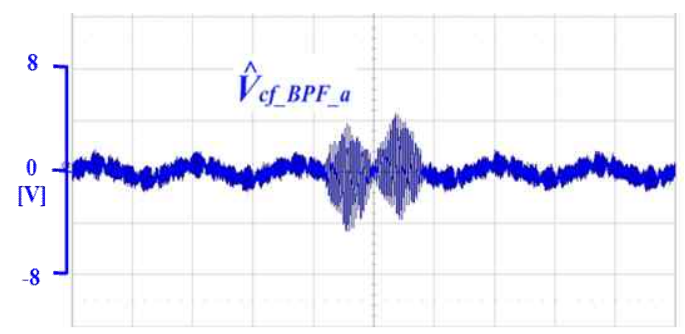

$<$ Before HPF application $>$

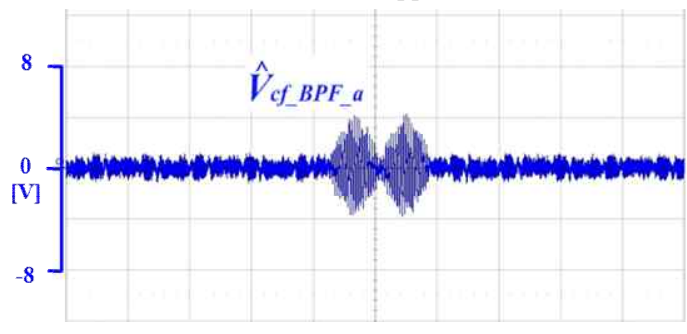

$<$ After HPF application>

(b) Experiment.

Fig. 21. Removal of low-order harmonic using HPF. 


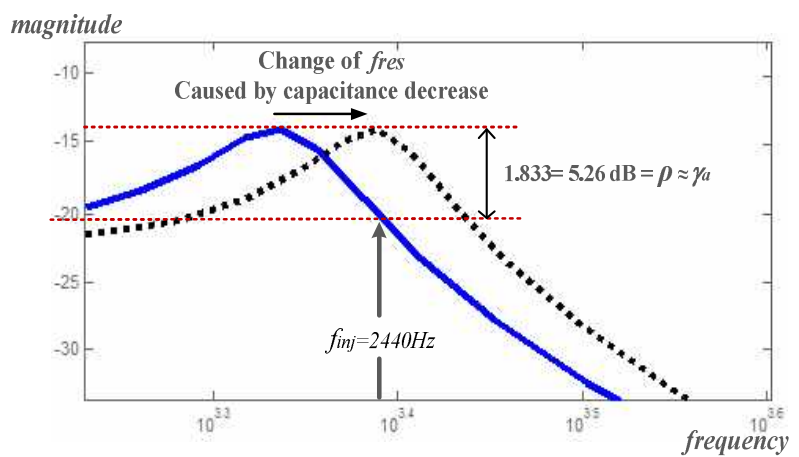

Fig. 22. Algorithm verification through comparison of results

$$
\begin{array}{rl|l}
\hat{V}_{c f_{-} H P F_{-} a}(n)= & \frac{2-T_{\text {samp }} \omega_{H P F}}{2+T_{\text {samp }} \omega_{H P F}}\left(\hat{V}_{c f_{-} H P F_{-} a}(n-1)\right) \\
& +\frac{T_{\text {samp }} \omega_{H P F}}{2+T_{\text {samp }} \omega_{H P F}}\left(\hat{V}_{c f_{-} a}(n)+\hat{V}_{c f_{-} a}(n-1)\right) & \begin{array}{l}
T_{\text {oump }}=50 \mu s \\
\omega_{H P P}=2 \pi * 800[\mathrm{rad} / \mathrm{s}]
\end{array}
\end{array}
$$

When the capacitance is decreased up to $80 \%$ of the initial value, the proportion value $\gamma_{a}$ by an experiment is increased up to 1.85 as expressed in (26) and the proportion value $\rho$ from two calculated value of (27) is obtained as 1.83 by the transfer function of the LCL-filter as shown in (28).

$$
\begin{gathered}
\gamma_{a}=\frac{\hat{V}_{c f \_a v e \_a b c_{f} \text { fult }}}{\hat{V}_{c f \_a v e \_a b c_{\text {_intial }}}}=\frac{3.62}{1.95}=1.85 \\
\omega_{\text {inj }} M_{\text {intial }}=1335, \omega_{\text {inj }} M_{\text {fault }}=2148 \\
\rho=\frac{\omega_{\text {inj }} M_{\text {fault }}}{\omega_{\text {inj }} M_{\text {initial }}}=1.83
\end{gathered}
$$

Fig. 22 shows that $\gamma a$ and $\rho$ are equal to the difference (5.26 $\mathrm{dB})$ of the $\mathrm{dB}$ gain between the bode-plot of the initial capacitance and the bode-plot of the faulty one at the $f_{i n j}$.

\section{CONCLUSIONS}

This paper has proposed a method for the replacement time and the deterioration diagnosis of the film capacitor in the LCL-filter. The resonant frequency component of $80 \%$ from the initial capacitance was injected into the reference voltage during one period of the grid frequency. The response of the injection appears in the capacitor voltage according to the gain of the LCL filter. The BPF and the HPF are used to detect the only response from the injected component. The absolute value of the response through the BPF and HPF is averaged. Also, through the transfer function of LCL filter, the magnitude gain according to each frequency can be calculated exactly. As a result, the deterioration fault of the filter-side capacitor is determined through the comparison between the experimental value and calculated value. The algorithm was verified through the simulations and experiments. Finally, the determination of the capacitor replacement time in the LCL-filter must be carefully observed, since it has a negative effect on the grid-connected PWM converter system; thus, the proposed algorithm can be a good solution to increase the reliability and safety of the whole system.

\section{ACKNOWLEDGMENT}

This work has been supported by the Korea Institute of Energy Technology Evaluation and Planning(KETEP) funded by Ministry of Knowledge Economy in 2011(No. 20112010100030-11-2-300).

\section{REFERENCES}

[1] E. Twining and D. G. Holmes, "Grid current regulation of a three-phase voltage source inverter with an LCL input filter," IEEE Trans. Power Electron., Vol. 18, No. 3, pp. 888-895, May 2003.

[2] R. Wu, S. B.Dewan, and G. R. Slemon, "Analysis of an ac-to-dc voltage source converter using PWM with phase and amplitude control," IEEE Trans. Ind. Appl., Vol. 27, No. 3, pp. 355-364, Mar./Apr. 1991.

[3] M. Malinowksi, M. P. Kazmierkowski, S. Hansen, F. Blaabjerg, and G. Marques, "Virtual flux based direct power control of three-phase PWM rectifiers," IEEE Trans. Ind. Appl., Vol. 37, No. 4, pp. 1019-1027, Jul./Aug. 2001.

[4] M. Malinowksi, M. P. Kazmierkowski, S. Hansen, F. Blaabjerg, and G. Marques, "Virtual flux based direct power control of three-phase PWM rectifiers," IEEE Trans. Ind. Appl., Vol. 37, No. 4, pp. 1019-1027, Jul./Aug. 2001.

[5] C. Cecati, A. Dell' Aquila, M. Liserre, and A. Ometto, "A fuzzy-logic based controller for active rectifier," IEEE Trans. Ind. Appl., Vol. 39, No.1, pp. 105-112, Jan./Feb. 2003.

[6] C. Cecati, A. Dell'Aquila, A. Lecci, and M. Liserre, "Implementation issues of a fuzzy-logic-based three-phase active rectifier employing only voltage sensors," IEEE Trans. Ind. Electron., Vol. 52, No. 2, pp. 378-385, Apr. 2005.

[7] W. A. Hill and S. C. Kapoor, "Effect of two-level PWM sources on plant power system harmonics," in Conf. Rec. IEEE-IAS Annu. Meeting, pp. 1300-1306, 1998.

[8] V. Blasko and V. Kaura, "A novel control to actively damp resonance in input lc filter of a three-phase voltage source converter," IEEE Trans. Ind. Appl., Vol. 33, No. 2, pp. 542-550, Mar./Apr. 1997.

[9] H. R. Karshenas and H. Saghafi, "Basic criteria in designing LCL filters for grid-connected converters," Industrial Electronics, 2006 IEEE International Symposium, Vol. 3, pp. 1996-2000, 2006.

[10] Y. Lang, D. Xu, S. R. Hadianamrei, and H. Ma, "A Novel design method of LCL type utility interface for three-phase voltage source rectifier," in Proc. IEEE- PESC '05 36th, pp. 313-317, Jun. 2005.

[11] M. T. Bina and E. Pashajavid, "An efficient procedure to design passive LCL-filters for active power filters," Electric Power Systems Research 79, pp. 606-614, 2009.

[12] M. Liserre, F. Blaabjerg and S. Hansen, "Design and control of an LCL-filter-based three-phase active rectifier," IEEE Trans. Ind. Appl., Vol. 41, pp. 1281-1291, 
May 2005.

[13] S. Tang, L. Peng, and Y. Kang, "Active damping method using grid-side current feedback for active power filters with LCL filters," Journal of Power Electronics, Vol. 11, No. 3, pp. 311 318, May 2011.

[14] F. Liu, Y. Zhou, S. Duan, J. Yin, B. Liu, and F. Liu, "Parameter design of a two-current-loop controller used in a grid-connected inverter system with LCL filter," IEEE Trans. Ind. Electron., Vol. 56, No. 11, pp. 4483 4491, Nov. 2009.

[15] M. Liserre, F. Blaabjerg, and S. Hansen, "Design and control of an LCL-filter-based three-phase active rectifier," IEEE Trans. Ind. Appl., Vol. 41, No. 5, pp. 1281 1291, Sep./Oct. 2005.

[16] EMERSON Network Power company, Capacitor Age and Capacitors Have an End of Life.

[17] G. M. Buiatti, S. M. A. Cruz, and A. J. M. Cardoso, "Lifetime of film capacitors in single-phase regenerative induction motor drives," IEEE International Symposium SDEMPED 2007, pp. 356 362, Sep. 2007.

[18] M. H. El-Husseini, P. Venet, G. Rojat, and M. Fathallah, "Effect of the geometry on the aging of metalized polypropylene film capacitors," IEEE 32nd Annual PESC. 2001, Vol. 4, pp. 2061-2066, Jun. 2001.

[19] L. Hua, L. Fuchang, and Z. Heqing, "Study on metallized film capacitor and its voltage maintaining performance," Vol. 45, No. 1, pp. 327 330, Jan. 2009.

[20] A. G. Abo-Khalil and Dong Choon Lee, "DC-link capacitance estimation in AC/DC/AC PWM converters using voltage injection," IEEE Trans. Ind. Appl., Vol. 44, No. 5, pp. 1631-1637, Sep./Oct. 2008.

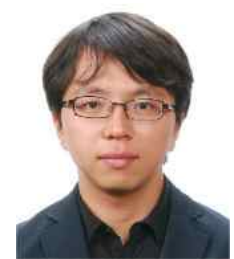

Hong-Jun Heo was born in Uiryeong, Korea, in 1986. He received the B.S. in electrical engineering from Pusan National University, Busan, Korea, in 2011. He is currently working toward the M.S. degree at Pusan National University. His research interests include high speed generators and grid-connected DC-AC converters.

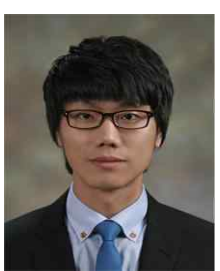

Won-Sang Im was born in Busan, Korea, in 1981. He received the B.S. and M.S. degrees in Electrical Engineering from Pusan National University, Busan, Korea, in 2007 and 2009, respectively, where he is currently working toward the Ph.D. degree. His research interests include power conversion, electric machine drives, and their diagnosis and fault-tolerance.

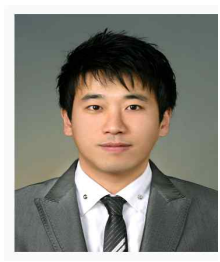

Jang-Sik Kim was born in Mokpo, Korea, in 1983. He received the B.S. degree in electrical engineering from Korea Maritime University, in 2010, and the M.S. degrees in electrical engineering from Pusan National University, Busan, Korea, in 2012. Since 2012, he has been with LG Electronics Company Gyeongnam, Korea. His research interests are control for home appliances, electric machines and power converters.

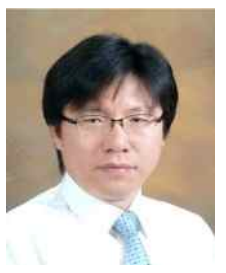

Jang-Mok Kim received the B.S. from Pusan National University, Korea, in 1988, and the M.S. and Ph.D. degrees from the Department of Electrical Engineering, Seoul National University, Seoul, Korea, in 1991 and 1996, respectively. From 1997 to 2000, he was a Senior Research Engineer with the Korea Electrical Power Research Institute (KEPRI). Since 2001, he has been with the School of Electrical Engineering, PNU, where he is currently a Research Member with the Research Institute of Computer Information and Communication, a Faculty Member, and a head of LG Electronics Smart Control Center. As a Visiting Scholar, he joined the Center for Advanced Power Systems (CAPS), Florida State University, in 2007. His research interests include the control of electric machines, electric vehicle propulsion, and power quality. 